\title{
Effect of Zebularine in Comparison to and in Combination with Trichostatin A on CIP/KIP Family (p21Cip1/Waf1/Sdi1, p27Kip1, and p57Kip2), DNMTs (DNMT1, DNMT3a, and DNMT3b), Class I HDACs (HDACs 1, 2,3) and Class II HDACs (HDACs 4, 5, 6) Gene Expression, Cell Growth Inhibition and Apoptosis Induction in Colon Cancer LS 174T Cell Line
}

\author{
Masumeh Sanaei, Fraidoon Kavoosi*
}

\begin{abstract}
Background: A pattern of epigenetic modifications and changes, DNA methylation and histone modification, is central to many human cancers. A variety of tumor suppressor genes (TSGs) have been demonstrated to be silenced because of histone deacetylation and DNA hypermethylation in several cancers. Recent in vitro studies have shown that two known mechanisms of epigenetic alteration consisting of methylation and histone deacetylation seem to be the best candidate mechanisms for inactivation of CIP/KIP family ( 2 21 Cipl/Wafl/Sdil, and $p 27 \mathrm{Kip} 1$ ) in numerous cancers. Numerous investigations have indicated that DNA demethylating and histone deacetylase inhibitors (HDACIs) can restore the $C I P / K I P$ family gene expression. Previously, we evaluated the effect of trichostatin A (TSA) and 5-aza-2'-deoxycytidine (5-AZA-CdR) on hepatocellular carcinoma (HCC). The present study was designed to

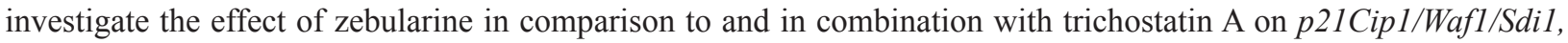
p27Kip1,p57Kip2, DNMT1, DNMT3a and DNMT3b, Class I HDACs (HDACs 1, 2, 3) and Class II HDACs (HDACs $4,5,6)$ gene expression, cell growth inhibition and apoptosis induction in colon cancer LS 174T cell line. Materials and Methods: The colon cancer LS 174T cell line was cultured and treated with zebularine and TSA. To determine cell viability, apoptosis, and the relative expression level of the genes, MTT assay, cell apoptosis assay, and qRT-PCR were done respectively. Results: Both compounds significantly inhibited cell growth, and induced apoptosis. Furthermore, both compounds increased p21Cip1/Wafl/Sdil, p27Kipl, and p57Kip2 significantly. Additionally, zebularine and TSA decreased DNMTs and HDACs gene expression respectively. Conclusion: The zebularine and trichostatin A can reactivate the CIP/KIP family through inhibition of DNMTs and HDACs genes activity.
\end{abstract}

Keywords: Zebularine- trichostatin- CIP/KIP family- colon cancer

Asian Pac J Cancer Prev, 21 (7), 2131-2139

\section{Introduction}

A pattern of epigenetic modifications and changes, DNA methylation and histone modification, is central to many human cancers. Posttranslational modifications affect chromatin structure and compaction resulting in changes in cell behavior and altered gene expression. Aberrant altered epigenomic patterns and gene expression are significant features of many cancers. Epigenetic modifications comprising DNA methylation, histone methylation, and histone acetylation plays an important role in the induction and progression of numerous cancers (Ellis et al., 2009). In fact, dysregulated epigenetic modifications play a significant role in driving cancer development and progression. A variety of tumor suppressor genes (TSGs) have been demonstrated to be silenced in several cancers. Indeed, the TSGs silencing is accompanied by histone deacetylation and DNA hypermethylation (Bachman et al., 2003). The mammalian somatic cell cycle is an ordered, tightly-regulated process with multiple checkpoints. The cycle is divided into four phases comprising initial growth (G1), DNA synthesis (S), a gap (G2), and mitosis (M). The molecular machinery of the cell cycle is a family of enzymes, the cyclin-dependent kinases (Cdks). The active form of these enzymes is a complex consisting of a kinase and a cyclin. Both cyclin and Cdk are positive regulators of cell cycle progression whereas, cyclin-dependent kinase inhibitors 
(CKIs) are negative regulators of cell cycle which stop or break the cycle. These negative inhibitors comprise two families including $I N K$ and $C I P / K I P$ families. The $I N K$ family consists of INK4A (p16), INK4B (p15), INK4C (p18), and INK4D (p19). The CIP/KIP family includes CIP1 (p21), KIP1 (p27), and KIP2 (p57) (Park et al., 2003). Recent in vitro studies have shown that two known mechanisms of epigenetic alteration consisting, methylation and histone deacetylation seem to be the best candidate mechanisms for inactivation of $C I P / K I P$ family in numerous cancers such as gastric cancer (Shin et al., 2000; Borges et al., 2010), lung cancer (Fang et al., 2002), hepatocellular carcinoma (HCC), pancreatic cancers, and acute myeloid leukemia (Kikuchi et al., 2002), and colon cancer (Colo-320 and SW1116) (Fang et al., 2004). There are several reports regarding the association between overexpression of DNA methyltransferases 1,2 and 3 and DNA methylation in various cancers comprising gastric cancer (Ding et al., 2008), colon cancer HCT116, LS180, HT29/219, Caco2, and SW742 cell lines (Sarabi et al., 2015). Furthermore, the overexpression of class $I$ and $I I$ $H D A C$ has been reported in colon cancer (Mariadason., 2008). Silenced TSGs are obvious targets for reactivation by DNA methyltransferase inhibitors (DNMTIs) such as 5-aza-2'-deoxycytidine (5-Aza-CdR), 5-azacytidine (5-Aza-CR) and zebularine. Numerous investigations have indicated that zebularine, a general inhibitor of DNA methylation, inhibits DNMTs in human breast cancer $M D A-M B-231$ and $M C F-7$ (Billam et al., 2010), $T 24$ bladder carcinoma (Ben-Kasus et al., 2005), colon cancer SW480 cells, HT29, SW48 and HCT116 (Ikehata et al., 2014). Besides, it has been identified that histone deacetylase inhibitors (HDACIs) can suppress class $I$ and $I I H D A C$ in colon cancer (Mariadason., 2008). Previously, we evaluated the effect of trichostatin A(TSA) on HCC (Sanaei et al., 2017; Sanaei et al., 2018; Leu et al., 2003) and also the effect of DNA demethylating agent 5-AZA-CdR on this cancer (Sanaei et al., 2019). The present study was designed to investigate the effect of zebularine and trichostatin A on p21Cip1/Wafl/Sdil, p27Kip1, p57Kip2, DNMT1, DNMT3a and DNMT3b, Class I HDACs (HDACs 1, 2, 3) and Class II HDACs (HDACs 4, 5, 6) gene expression, cell growth inhibition and apoptosis induction in colon cancer $L S 174 T$ cell line.

\section{Materials and Methods}

\section{Materials}

The human colon cancer LS 174T cell line was kindly provided from the National Cell Bank of Iran-Pasteur Institute and maintained in Dulbecco's modified Eagle's medium (DMEM) supplemented with antibiotics and fetal bovine serum $10 \%$ in a humidified atmosphere of $5 \% \mathrm{CO}_{2}$ in air at $37^{\circ} \mathrm{C}$. All reagents (zebularine and TSA), kits, and instruments used in RNA extraction, reverse transcription, and real-time PCR were provided as obtained previously (Sanaei M et al., 2017; Sanaei M et al., 2018; Sanaei M et al., 2019).

\section{Cell culture and cell viability}

The colon cancer LS 174T cell viability was measured using 3 (4,5 dimethyl 2 thiazolyl) 2, 5 diphenyl $2 \mathrm{H}$ tetrazolium bromide (MTT) assay. The LS 174T cells were cultured and seeded in 96-well plates at a density of $4 \times 10^{5}$ cells per well and treated with zebularine $(0$, $10,25,50,100$, and $200 \mu \mathrm{M})$ and $\operatorname{TSA}(0,1,5,10,25$, and $50 \mu \mathrm{M}$ ) for 24 and $48 \mathrm{~h}$. The control groups were treated with Dimethyl sulfoxide (DMSO), $0.05 \%$, only. After incubation for 24 and $48 \mathrm{~h}$, the LS 174T cells were exposed to MTT, MTT $(0.5 \mathrm{mg} / \mathrm{mL})$ was added to each well for $4 \mathrm{~h}$. Finally, the MTT metabolite, the blue MTT formazan, was dissolved in DMSO $(200 \mathrm{~mL})$ and the optical density was detected by a microplate reader at a wavelength of $570 \mathrm{nM}$. Each experiment was repeated three times (triplicates).

\section{Cell apoptosis assay}

To determine the apoptotic LS $174 \mathrm{~T}$ cells, the cells were treated with cultured and seeded at a density of $4 \times 10^{5}$ cells/well and treated with zebularine $(50 \mu \mathrm{M})$ and TSA $(5 \mu \mathrm{M})$ for 24 and $48 \mathrm{~h}$. Following treatment, the cells were harvested by trypsin and washed twice with PBS and then resuspended in Binding buffer (1x). Subsequently, the cells were stained with annexin V-FITC $(5 \mu \mathrm{l})$ and propidium iodide $(5 \mu \mathrm{l})$ in the dark at room temperature for $15 \mathrm{~min}$. Finally, the LS 174T apoptotic cells were counted by FACScan flow cytometry (Becton Dickinson, Heidelberg, Germany).

\section{Real-time Quantitative Reverse Transcription PolymeraseChain Reaction ( $q R T-P C R$ )}

The qRT-PCR was performed to determine the relative expression level of 2 21 Cip1/Wafl/Sdi1, p27Kip1, p57Kip2, DNMT1, DNMT3a, DNMT3b, Class I HDACs (HDACs 1, 2, 3) and Class II HDACs (HDACs 4, 5, 6) genes. The colon cancer LS $174 \mathrm{~T}$ cells were cultured at a density of $4 \times 10^{5}$ cells/well and treated with zebularine $(50 \mu \mathrm{M})$ and TSA $(5 \mu \mathrm{M})$, as alone and combined, for 24 and $48 \mathrm{~h}$, based on IC5o values. After 24 and $48 \mathrm{~h}$ of incubation, the total RNA was harvested using the RNeasy kit (Qiagen, Valencia, CA) according to the manufacturer protocol and treated by RNase-free DNase (Qiagen). The RNA was transcribed to complementary DNA (cDNA). QRT-PCR was done to assess the expression level of the mentioned genes as described previously (Sanaei et al., 2019). The program for the PCR was as we reported previously (Sanaei et al., 2019). The primer sequences of the genes are indicated in table1. GAPDH was used as an endogenous control. Data were analyzed using the comparative $\mathrm{Ct}(\Delta \Delta \mathrm{ct})$ method.

\section{Results}

Result of cell viability by the MTT assay

To test the effect of zebularine $(0,10,25,50,100$, and $200 \mu \mathrm{M})$ and TSA $(0,1,5,10,25$, and $50 \mu \mathrm{M})$ on the colon cancer LS $174 \mathrm{~T}$ cell viability, MTT assay was utilized. Our findings showed that the rate of cell growth inhibition was significantly increased in than that in control groups after 24 and 48 h. Results showed that the number of viable LS 174T cells decreased significantly, as the concentration of the compounds and duration increased; 
Table 1. The Primer Sequences of p21Cip1/Waf1/Sdi1, p27Kip1, p57Kip2, DNMT1, DNMT3a, DNMT3b, Class I HDACs (HDACs 1, 2, 3) and Class II HDACs (HDACs 4, 5, 6)

\begin{tabular}{|c|c|c|}
\hline Primer Name & Primer Sequences (5' to $\left.3^{\prime}\right)$ & References \\
\hline DNMT1 Forward & GAG GAA GCT GCT AAG GAC TAG TTC & Sanaei et al., 2018 \\
\hline DNMT1 Reverse & ACT CCA CAA TTT GAT CAC TAA ATC & Sanaei et al., 2018 \\
\hline DNMT3a Forward & GGA GGC TGA GAA GAA AGC CAA GGT & Sanaei et al., 2018 \\
\hline DNMT3a Reverse & TTT GCC GTC TCC GAA CCA CAT GAC & Sanaei et al., 2018 \\
\hline P21 Forward & AGG CGC CAT GTC AGA ACC GGC TGG & Sanaei et al., 2019 \\
\hline P21 Reverse & GGA AGG TAG AGC TTG GGC AGG C & Sanaei et al., 2019 \\
\hline P 27 Forward & ATG TCA AAC GTG CGA GTG TCT AAC & Sanaei et al., 2019 \\
\hline P 27 Reverse & TTA CGT TTG ACG TCT TCT GAG GCC A & Sanaei et al., 2019 \\
\hline P 57 Forward & GCGGCGATCAAGAAGCTGTC & Sanaei et al., 2019 \\
\hline P 57 Reverse & CCGGTTGCTGCTACATGAAC & Sanaei et al., 2019 \\
\hline DNMT3b Forward & TAC ACA GAC GTG TCC AAC ATG GGC & Leu et al., 2003 \\
\hline DNMT3b Reverse & GGA TGC CTT CAG GAA TCA CAC CTC & Leu et al., 2003 \\
\hline GAPDH Forward & TCCCATCACCATCTTCCA & Jin et al., 2008 \\
\hline GAPDH Reverse & CATCACGCCACAGTTTCC & Jin et al., 2008 \\
\hline HDAC1 Forward & GACACGCCAAGTGTGTGGAA & Song et al., 2015 \\
\hline HDAC1 Reverse & CCTCCCAGCATCAGCATAGG & Song et al., 2015 \\
\hline HDAC2 Forward & ACATGAGCAATGCGGAGAAAT & Song et al., 2015 \\
\hline HDAC2 Reverse & TCTGCCATCTTGTGGTACAGTGA & Song et al., 2015 \\
\hline HDAC3 Forward & CCTTTTCCAGCCGGTTATCA & Song et al., 2015 \\
\hline HDAC3 Reverse & ACAATGCACGTGGGTTGGT & Song et al., 2015 \\
\hline HDAC4 Forward & TCAGATCGCCAACACATTCG & Song et al., 2015 \\
\hline HDAC4 Reverse & ACGGGAGCGGTTCTGTTAGA & Song et al., 2015 \\
\hline HDAC5 Forward & CCATTGGAGACGTGGAGTACCT & Song et al., 2015 \\
\hline HDAC5 Reverse & GCGGAGACTAGGACCACATCA & Song et al., 2015 \\
\hline HDAC6 Forward & TCGCTGCGTGTCCTTTCAG & Song et al., 2015 \\
\hline HDAC6 Reverse & GCTGTGAACCAACATCAGCTCTT & Song et al., 2015 \\
\hline
\end{tabular}

indicating a dose- and duration-dependent relationship $(\mathrm{P}<0.001)$, Figure 1. The $\mathrm{IC}_{50}$ values were determined with approximately 50 and $5 \mu \mathrm{M}$ for zebularine and TSA respectively.

Result of cell apoptosis assay

Flow cytometric analysis was achieved to determine whether zebularine $(50 \mu \mathrm{M})$ and TSA $(5 \mu \mathrm{M})$ can induce apoptosis in colon cancer LS 174T line. The percentage of treated and un-treated LS 174T apoptotic cells was evaluated by staining with annexin V-FITC and PI after 24 and $48 \mathrm{~h}$ of treatment. After treatment with zebularine and TSA, as alone and combined, the apoptosis percentage increased significantly as shown in Table 2 and Figures
2-4. Both compounds had a time-dependent manner. The apoptotic effect of TSA was stronger than that of zebularine. Further, maximum apoptosis was seen in the groups treated with combined agents, Figure 5.

\section{Result of determination of genes expression}

The effect of zebularine $(50 \mu \mathrm{M})$ and TSA $(5 \mu \mathrm{M})$ on the p21Cip1/Waf1/Sdi1, p27Kip1, p57Kip2, DNMT1, DNMT3a, DNMT3b, Class I HDACs (HDACs 1, 2, 3) and Class II HDACs (HDACs 4, 5, 6) gene expression was investigated by quantitative real-time RT-PCR analysis. The result indicated that treatment of LS 174T cells with zebularine $(50 \mu \mathrm{M})$ and TSA $(5 \mu \mathrm{M})$ for 24 and $48 \mathrm{~h}$ reactivated the $p 21 \mathrm{Cip} 1 / \mathrm{Waf1} / \mathrm{Sdi1}$, p27Kip1, p57Kip2

Table 2. Percentage of Apoptosis in the Groups Treated with Zebularine and TSA, as Alone and Combined, at Different Periods.

\begin{tabular}{lcccc}
\hline Drug & Dose $/ \mu \mathrm{M}$ & Duration/ h & Apoptosis $\%$ & P-value \\
\hline Zebularine & 50 & 24 & 8.07 & $\mathrm{P}<0.001$ \\
& 50 & 48 & 10.07 & $\mathrm{P}<0.001$ \\
TSA & 5 & 24 & 10.35 & $\mathrm{P}<0.001$ \\
& 5 & 48 & 13.8 & $\mathrm{P}<0.001$ \\
Zebularine/TSA & $50 / 5$ & 24 & 85.11 & $\mathrm{P}<0.001$ \\
& $50 / 5$ & 48 & 97.43 & $\mathrm{P}<0.001$ \\
\hline
\end{tabular}


Table 3. The Relative Expression Level of DNMTs (DNMT1, DNMT3a, and DNMT3b), CIP/KIP Family (p21Cip1/ Waf1/Sdi1, p27Kip1, and p57Kip2) HDAC1, HDAC2, and HDAC3 Genes

\begin{tabular}{|c|c|c|c|c|c|c|}
\hline Cell line & Gene & Drug & Dose $(\mu \mathrm{M})$ & Duration (h) & Expression & $P$-value \\
\hline LS 174T & DNMT1 & Zebularine & 50 & 24 & 0.7 & 0.023 \\
\hline LS 174T & DNMT1 & Zebularine & 50 & 48 & 0.55 & 0.001 \\
\hline LS 174T & DNMT3a & Zebularine & 50 & 24 & 0.68 & 0.014 \\
\hline LS 174T & DNMT3a & Zebularine & 50 & 48 & 0.5 & 0.001 \\
\hline LS 174T & DNMT3b & Zebularine & 50 & 24 & 0.67 & 0.011 \\
\hline LS 174T & DNMT3b & Zebularine & 50 & 48 & 0.44 & 0.01 \\
\hline LS 174T & $P 21$ & Zebularine & 50 & 24 & 1.7 & 0.004 \\
\hline LS 174T & $P 21$ & Zebularine & 50 & 48 & 1.9 & 0.001 \\
\hline LS 174T & $P 27$ & Zebularine & 50 & 24 & 1.8 & 0.001 \\
\hline LS 174T & $P 27$ & Zebularine & 50 & 48 & 2.1 & 0.001 \\
\hline LS 174T & P57 & Zebularine & 50 & 24 & 1.6 & 0.001 \\
\hline LS $174 \mathrm{~T}$ & P57 & Zebularine & 50 & 48 & 2 & 0.001 \\
\hline LS 174T & $H D A C 1$ & Trichostatin A & $5 \mu \mathrm{M}$ & 24 & 0.58 & 0.001 \\
\hline LS 174T & $H D A C 1$ & Trichostatin A & $5 \mu \mathrm{M}$ & 48 & 0.4 & 0.001 \\
\hline LS 174T & $H D A C 2$ & Trichostatin A & $5 \mu \mathrm{M}$ & 24 & 0.56 & 0.002 \\
\hline LS 174T & $H D A C 2$ & Trichostatin A & $5 \mu \mathrm{M}$ & 48 & 0.38 & 0.001 \\
\hline LS 174T & $H D A C 3$ & Trichostatin A & $5 \mu \mathrm{M}$ & 24 & 0.57 & 0.001 \\
\hline LS 174T & $H D A C 3$ & Trichostatin A & $5 \mu \mathrm{M}$ & 48 & 0.37 & 0.001 \\
\hline LS 174T & $P 21$ & Trichostatin A & $5 \mu \mathrm{M}$ & 24 & 2.2 & 0.001 \\
\hline LS 174T & $P 21$ & Trichostatin A & $5 \mu \mathrm{M}$ & 48 & 2.8 & 0.001 \\
\hline LS 174T & $P 27$ & Trichostatin A & $5 \mu \mathrm{M}$ & 24 & 2 & 0.001 \\
\hline LS 174T & $P 27$ & Trichostatin A & $5 \mu \mathrm{M}$ & 48 & 2.4 & 0.001 \\
\hline LS 174T & P57 & Trichostatin A & $5 \mu \mathrm{M}$ & 24 & 2.3 & 0.001 \\
\hline LS 174T & P57 & Trichostatin A & $5 \mu \mathrm{M}$ & 48 & 2.7 & 0.001 \\
\hline
\end{tabular}

gene, down-regulated DNMT1, DNMT3a, DNMT3b, Class I HDACs (HDACs 1, 2, 3) and Class II HDACs (HDACs $4,5,6)$ gene expression. The CIP/KIP family (p21Cip1/ Waf1/Sdi1,p27Kip1, p57Kip2) genes were more sensitive to TSA compared with zebularine. It means that TSA had a more significant effect on the up-regulation of $p 21 \mathrm{Cip} 1 /$ Waf1/Sdi1, p27Kip1, p57Kip2, Figures 6-9.

\section{Discussion}

The mammalian cell cycle is regulated via interactions between cyclins and a family of negative cell cycle regulators classified into two families, the $C I P / K I P$ family, and the INK4 family. DNA methylation patterns and histone deacetylation of these families strongly correlate with tumorigenesis (Tsou et al., 2002). DNA methylation is catalyzed by DNMT1, DNMT3a, and $D N M T 3 b$. Furthermore, histone deacetylation is catalyzed by $H D A C s$. Therefore, DNMTs and HDACs induce hypermethylation and histone deacetylation respectively

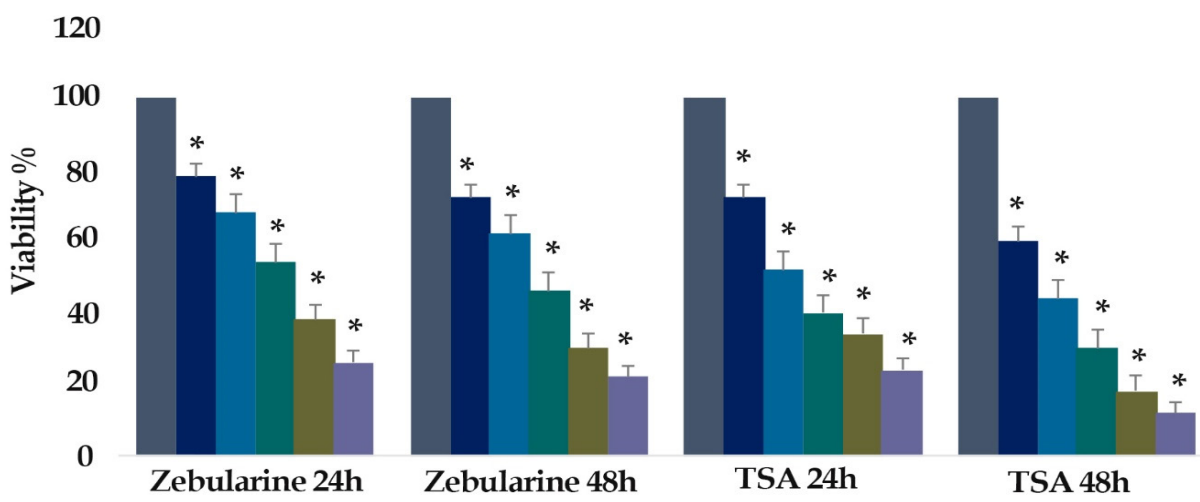

Figure 1. In Vitro Effects of Zebularine $(0,10,25,50,100$, and $200 \mu \mathrm{M})$ and TSA $(0,1,5,10,25$, and $50 \mu \mathrm{M})$ on LS $174 \mathrm{~T}$ Cells Viability Determined by MTT Assay at 24 and $48 \mathrm{~h}$. As shown, from right to the left, the first column of each group belongs to the control group. Values are means of three experiments in triplicate. Asterisks $(*)$ demonstrate significant differences between treated and untreated control groups. 

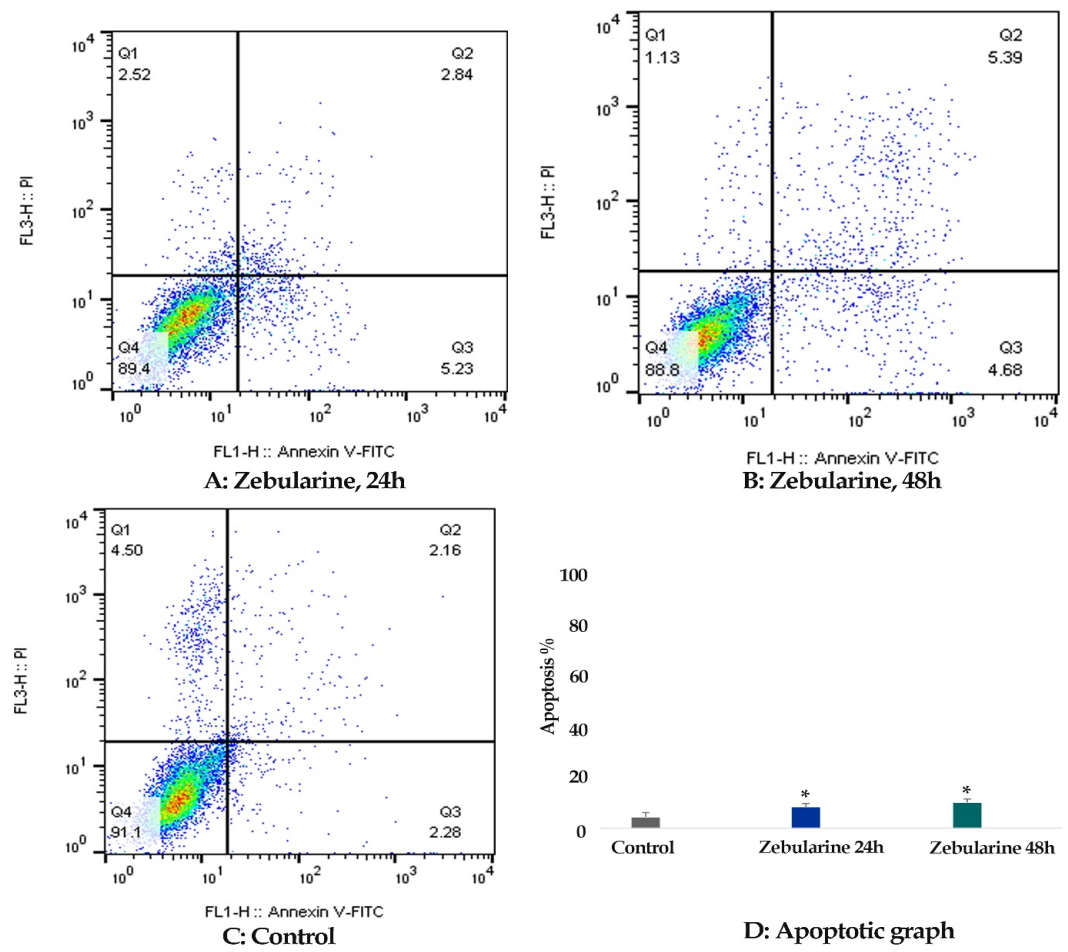

Figure 2. The Apoptotic Effect of Zebularine $(50 \mu \mathrm{M})$ on Colon Cancer LS 174T Line Cell versus Control Groups at Different Periods ( 24 and $48 \mathrm{~h}$ ). The cells were treated with this zebularine for 24 and $48 \mathrm{~h}$ and then the apoptotic effect was evaluated by flow cytometric analysis. Results were obtained from three independent experiments and were expressed as mean \pm standard error of the mean.

resulting in TSGs transcriptional repression and cancer induction (Li et al., 2007). The DNMTIs and HDACIs can reactivate epigenetically silenced TSGs (Yan et al., 2015). In the present study, zebularine and TSA reactivated the p21Cip1/Waf1/Sdi1, p27Kip1, p57Kip2 gene, downregulated DNMT1, DNMT3a, DNMT3b, Class I HDACs (HDACs 1, 2, 3) and Class II HDACs (HDACs 4, 5, 6) gene resulting in cell growth inhibition and apoptosis induction.
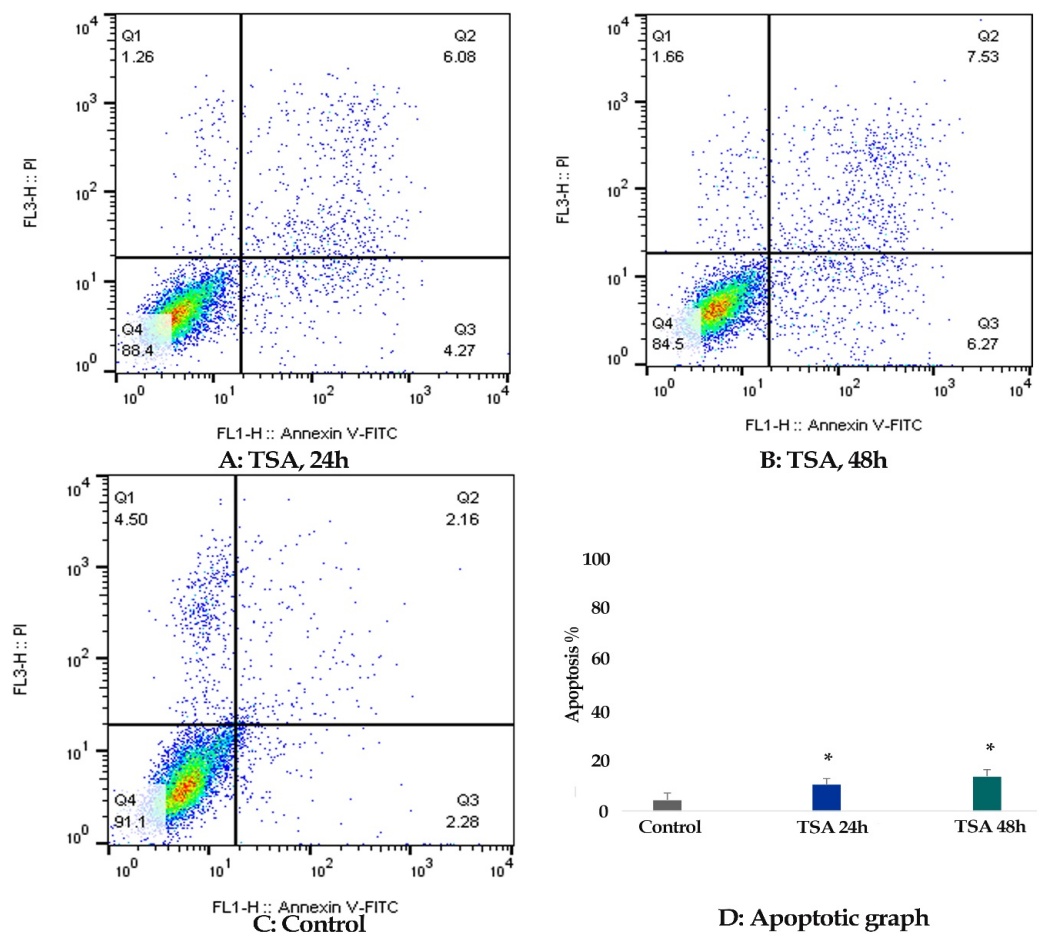

B: TSA, $\mathbf{4 8 h}$

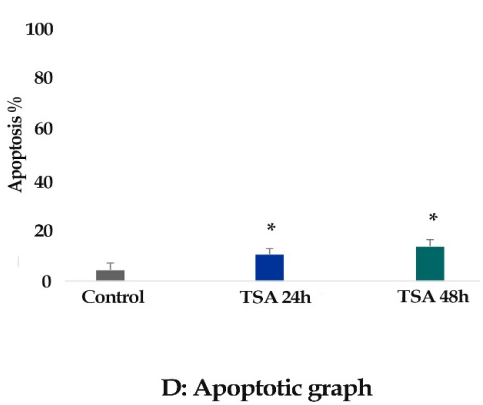

Figure 3. The Apoptotic Effect of TSA $(5 \mu \mathrm{M})$ on Colon Cancer LS 174T Line Cell versus Control Groups at Different Periods (24 and 48h). The cells were treated with this zebularine for 24 and $48 \mathrm{~h}$ and then the apoptotic effect was evaluated by flow cytometric analysis. Results were obtained from three independent experiments and were expressed as mean \pm standard error of the mean. 


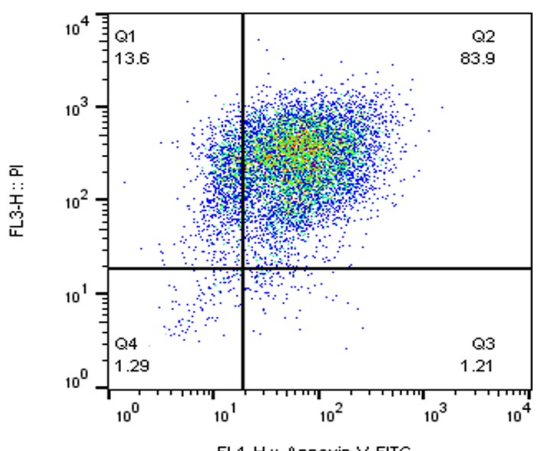

FL1-H:: Annexin V-FITC

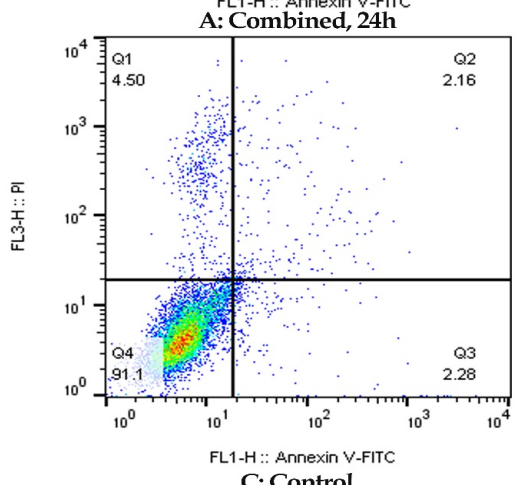

C: Control

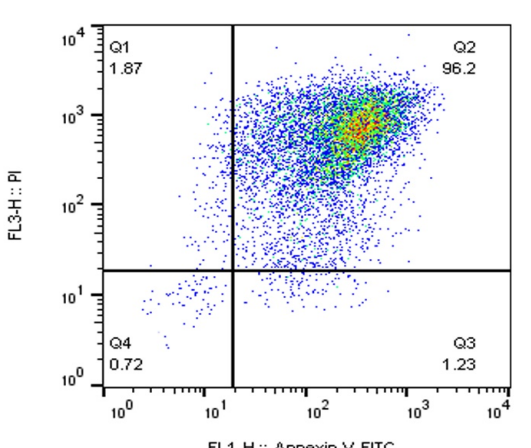

B: Combined, $48 \mathrm{~h}$

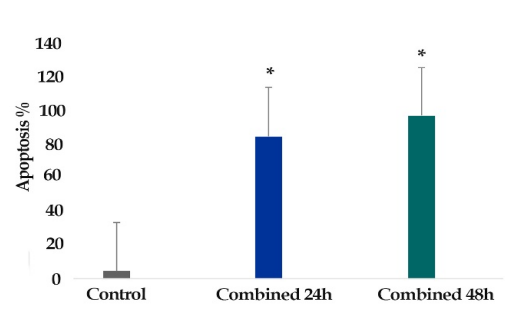

D: Apoptotic graph

Figure 4. The Apoptotic Effect of Zebularine $(50 \mu \mathrm{M})$ in Combination with TSA $(5 \mu \mathrm{M})$ on LS 180 Cell versus Control Groups at Different Periods (24 and 48h). The cells were treated with combined agents for 24 and $48 \mathrm{~h}$ and then the apoptotic effect was evaluated by flow cytometric analysis. Results were obtained from three independent experiments and were expressed as mean \pm standard error of the mean.

Table 4. The Relative Expression Level of p21Cip1/Waf1/Sdi1, p27Kip1, p57Kip2 Genes in the Groups Treated with Combined Treatment

\begin{tabular}{lcccccc}
\hline Cell line & Gene & Drug & Dose $(\mu \mathrm{M})$ & Duration $(\mathrm{h})$ & Expression & $P$-value \\
\hline LS 180 & $P 21$ & Zebularine/TSA & $25 / 5 \mu \mathrm{M}$ & 24 & 3.2 & 0.001 \\
LS 180 & $P 21$ & Zebularine/TSA & $25 / 5 \mu \mathrm{M}$ & 48 & 3.5 & 0.001 \\
LS 180 & $P 27$ & Zebularine/TSA & $25 / 5 \mu \mathrm{M}$ & 24 & 3.6 & 0.001 \\
LS 180 & $P 27$ & Zebularine/TSA & $25 / 5 \mu \mathrm{M}$ & 48 & 3.9 & 0.001 \\
LS 180 & $P 57$ & Zebularine/TSA & $25 / 5 \mu \mathrm{M}$ & 24 & 3.7 & 0.001 \\
LS 180 & $P 57$ & Zebularine/TSA & $25 / 5 \mu \mathrm{M}$ & 48 & 3.8 & 0.001 \\
\hline
\end{tabular}

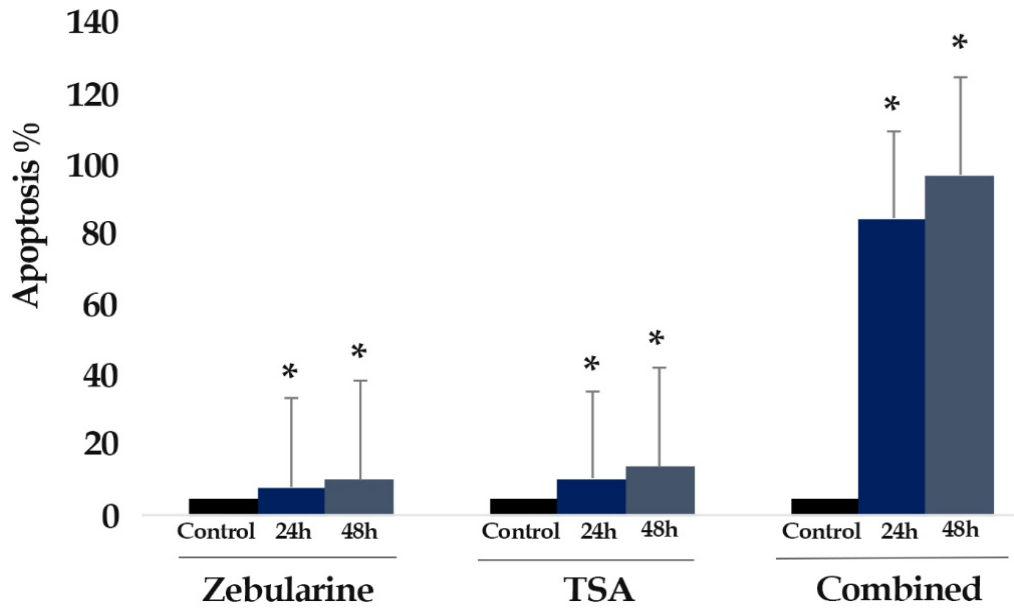

Figure 5. The Comparative Apoptotic Effects of Zebularine (50 $\mu \mathrm{M})$ in Comparison to and in Combination with TSA $(5 \mu \mathrm{M})$ on LS 174T Cells. Asterisks $(*)$ indicate significant differences between the treated and untreated control groups. As demonstrated above, TSA had a more significant apoptotic effect on LS 174T cells in comparison to zebularine. The combined treatment had a maximum effect on apoptosis. 
2.5
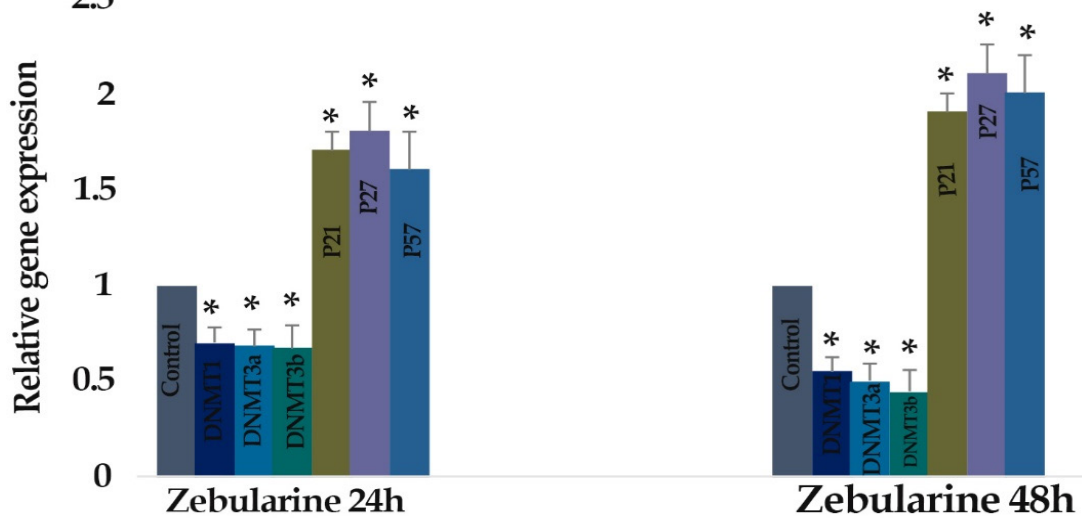

Figure 6. The Relative Expression Level of DNA Methyltransferases (DNMT1, 3a, and 3b), p21Cip1/Waf1/Sdi1, p27Kip1, and p57Kip2 in the LS 174T Cell Line Treated with Zebularine $(50 \mu \mathrm{M})$ versus Untreated Control Groups at Different Periods (24 and 48h). The first column of each group belongs to the untreated control group and the others belong to the treated cells with zebularine. Asterisks $\left.*^{*}\right)$ indicate significant differences between the treated and untreated groups.

3.5

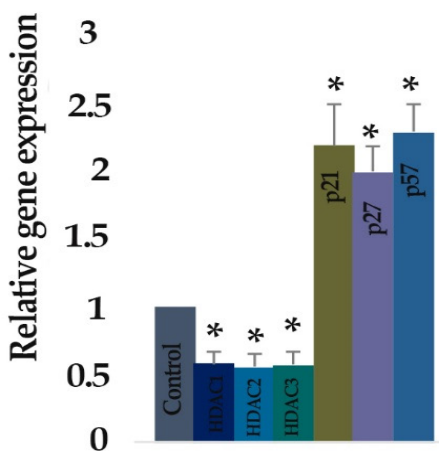

TSA 24h

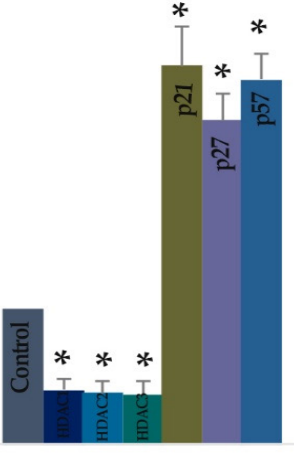

TSA $48 h$

Figure 7. The Relative Expression Level of Class I HDACs (HDACs 1, 2, 3), Class II HDACs (HDACs 4, 5, 6), p21Cip1/Waf1/Sdi1, p27Kip1, and p57Kip2 Gene in the LS 174T Cell Line Treated with TSA $(5 \mu \mathrm{M})$ versus Untreated Control Groups at Different Periods ( 24 and $48 \mathrm{~h}$ ). The first column of each group belongs to the untreated control group and the others belong to the treated cells with TSA. Asterisks $(*)$ indicate significant differences between the treated and untreated groups.
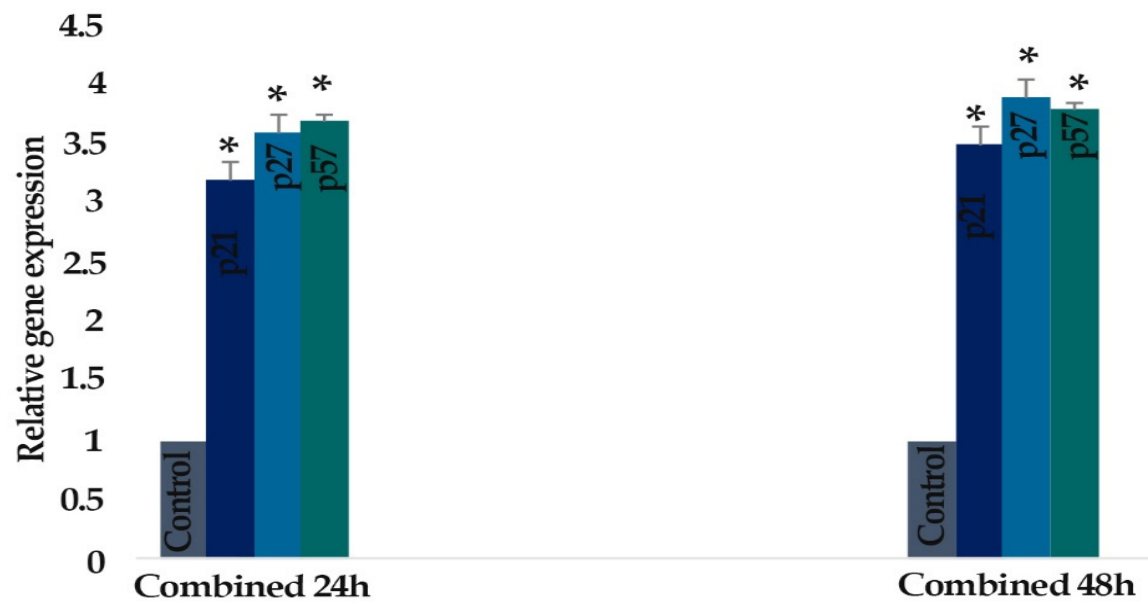

Figure 8. The Relative Expression Level of p21Cip1/Waf1/Sdi1, p27Kip1, and p57Kip2 in the LS 174T Cell Line Treated with Zebularine $(50 \mu \mathrm{M})$ in Combination with TSA $(5 \mu \mathrm{M})$ versus Untreated Control Groups at Different Periods ( 24 and $48 \mathrm{~h}$ ). The first column of each group belongs to the untreated control group and the others belong to the treated cells with the combined components. Asterisks $\left(^{*}\right)$ indicate significant differences between the treated and untreated groups. 


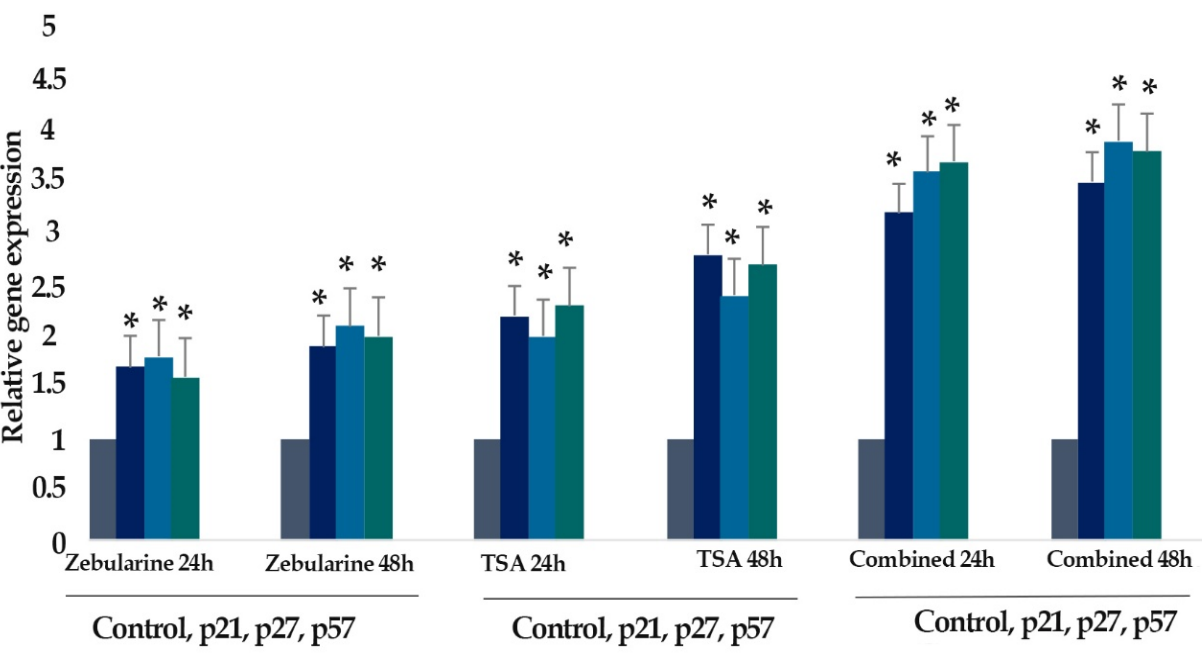

Figure 9. The Relative Expression Level of p21Cip1/Waf1/Sdi1, p27Kip1, and p57Kip2 in the LS 174T Cell Line Treated with Zebularine $(50 \mu \mathrm{M})$ and TSA $(5 \mu \mathrm{M})$, Individually and Combined, versus Untreated Control Groups at Different Periods (24 and 48h). The first column of each group belongs to the untreated control group and the others belong to the treated cells with the zebularine and TSA. Asterisks $\left({ }^{*}\right)$ indicate significant differences between the treated and untreated groups.

The CIP/KIP family (p21Cip1/Waf1/Sdi1, p27Kip1, p57Kip2) gene was more sensitive to TSA compared with zebularine. It means that TSA had a more significant effect on the up-regulation of 2 21Cip1/Waf1/Sdil, p27Kipl, p57Kip2. In consistent with our result, it has been reported that zebularine can restore 21Cip1/Wafl/Sdil in colon cancer $S W 48$ and $H T-29$ (Flis et al., 2014), CT15 and HT-29 colon cancer (Cheng et al., 2004). The other members of the DNMTI family act by the same pathway as reported for 5 -azacitidine. It reactivates p21Cip 1/ Wafl/Sdilin HCT 116 colon cancer cells (Jiemjit et al., 2008), p27Kip1 in colon cancer SW1116 cells (Lu et al., 2007), Caco2, RKO, SW48, SW480, Colo201, Colo205, Colo320, BM314, DLD-1, and HT29 (Kikuchi et al 2002). Further, we evaluated the molecular mechanism through which zebularine reactivate $p 21 \mathrm{Cip} 1 / \mathrm{Wafl} / \mathrm{Sdi1}$, p27Kip1, p57Kip2 gene and found that this agent targets some of DNMTIs (DNMT1, DNMT3a, and DNMT3b). A similar mechanism (DNMT inhibition) has been demonstrated in colon cancer HCT116 cells (Yang et al., 2013), HCC Hep G2 (Nakamura et al., 2013), cholangiocarcinoma cell lines TFK-1 and HuCCT1 (Nakamura et al., 2015). After assessment of the effect of TSA on p21Cip1/Wafl/Sdil, p27Kip1, p57Kip 2 gene expression, we further determined the effect of TSA on Class I HDACs (HDACs 1, 2, 3) and Class II HDACs (HDACs 4, 5, 6) gene expression. As we reported, this agent down-regulated both Class $I$ and II HDACs. Similarly, it has been shown that TSA down-regulates class $I$ and II HDACS in colon cancer cells $S W 620$, SW480, and DLD1 (Krishnan et al., 2010), class $I$ and II HDACs in human prostate cancer $L N C a P$ cells (Thakur et al., 2011). Further molecular mechanisms of TSA including down-regulation of HDAC8 in colon cancer cell line $S W 620$ (Hu et al., 2003), HDACs 5 and 8 in lung cancer, breast cancer, and skin cancer cells (Chang et al., 2012). As mentioned above, we only evaluated the effect of TSA on Class I and II HDACs in colon cancer. Therefore, the investigation of TSA on the other classes of HDACS is recommended.

In summary, our findings indicated that zebularine and TSA can down-regulate DNMT1, DNMT3a, DNMT3b, class I HDACs (HDACs 1, 2, 3) and class II HDACs (HDACs 4, 5, 6) resulting in reactivation of p21Cip1/ Waf1/Sdi1, p27Kip1, p57Kip2, cell growth inhibition and apoptosis induction of colon cancer $L S 174 T$ cell line.

\section{Acknowledgments}

This article was supported by the adjutancy of research of Jahrom University of Medical Sciences, Iran.

\section{Conflict of interest}

The authors report no conflict of interest.

\section{References}

Bachman KE, Park BH, Rhee I, et al (2003). Histone modifications and silencing prior to DNA methylation of a tumor suppressor gene. Cancer Cell, 3, 89-95.

Ben-Kasus T, Ben-Zvi Z, Marquez VE, et al (2005). Metabolic activation of zebularine, a novel DNA methylation inhibitor, in human bladder carcinoma cells. Biochem Pharmacol, 70, 121-33.

Billam M, Sobolewski MD, Davidson NE (2010). Effects of a novel DNA methyltransferase inhibitor zebularine on human breast cancer cells. Breast Cancer Res Treat, 120, 581-92.

Borges BDN, BURBANO RMR, et al (2010). Absence of CIP1/ KIP1 hypermethylation in gastric cancer patients from Northern Brazil. In Vivo, 24, 579-82.

Chang J, Varghese D, Gillam M, et al (2012). Differential response of cancer cells to HDAC inhibitors trichostatin A and depsipeptide. Br J Cancer, 106, 116.

Cheng JC, Yoo CB, Weisenberger DJ, et al (2004). Preferential response of cancer cells to zebularine. Cancer Cell, 6, 151-8.

Ding W-J, Fang J-Y, Chen X-Y, et al (2008). The expression and clinical significance of DNA methyltransferase proteins in human gastric cancer. Dig Dis Sci, 53, 2083-9.

Ellis L, Atadja PW, Johnstone RW (2009). Epigenetics in cancer: 
targeting chromatin modifications. Mol Cancer Ther, 8 , 1409-20.

Fang JY, Chen YX, Juan L, et al (2004). Epigenetic modification regulates both expression of tumor-associated genes and cell cycle progressing in human colon cancer cell lines: Colo-320 and SW1116. Cell Res, 14, 217.

Fang J-Y, Lu Y-Y (2002). Effects of histone acetylation and DNA methylation on p21WAF1 regulation. World J Gastroenterol, 8, 400 .

Flis S, Gnyszka A, Flis K (2014). DNA methyltransferase inhibitors improve the effect of chemotherapeutic agents in SW48 and HT-29 colorectal cancer cells. PLoS One, 9, 92305.

Hu E, Dul E, Sung C-M, et al (2003). Identification of novel isoform-selective inhibitors within class I histone deacetylases. J Pharmacol Exp Ther, 307, 720-8.

Ikehata M, Ogawa M, Yamada Y, et al (2014). Different effects of epigenetic modifiers on the cytotoxicity induced by 5-fluorouracil, irinotecan or oxaliplatin in colon cancer cells. Biol Pharm Bull, 37, 67-73

Jiemjit A, Fandy T, Carraway H, et al (2008). p21 WAF1/CIP1 induction by 5 -azacytosine nucleosides requires DNA damage. Oncogene, 27, 3615.

Jin KL, Pak JH, Park J-Y, et al (2008). Expression profile of histone deacetylases 1, 2 and 3 in ovarian cancer tissues. J Gynecol Oncol, 19, 185-90.

Kikuchi T, Toyota M, Itoh F, et al (2002). Inactivation of p57KIP2 by regional promoter hypermethylation and histone deacetylation in human tumors. Oncogene, 21, 2741.

Krishnan M, Singh AB, Smith J, et al (2010). HDAC inhibitors regulate claudin-1 expression in colon cancer cells through modulation of mRNA stability. Oncogene, 29, 305.

Leu Y-W, Rahmatpanah F, Shi H, et al (2003). Double RNA interference of DNMT3b and DNMT1 enhances DNA demethylation and gene reactivation. Cancer Res, 63, 6110-5.

Li L-C, Dahiya R (2007). Epigenetics of prostate cancer. Front Biosci, 12, 3377-97.

Lu R, Wang X, Chen Z-F, et al (2007). Inhibition of the extracellular signal-regulated kinase/mitogen-activated protein kinase pathway decreases DNA methylation in colon cancer cells. J Biol Chem, 282, 12249-59.

Mariadason JM (2008). HDACs and HDAC inhibitors in colon cancer. Epigenetics, 3, 28-37.

Nakamura K, Aizawa K, Nakabayashi K, et al (2013). DNA methyltransferase inhibitor zebularine inhibits human hepatic carcinoma cells proliferation and induces apoptosis. PLoS One, 8, 54036.

Nakamura K, Nakabayashi K, Aung KH, et al (2015). DNA methyltransferase inhibitor zebularine induces human cholangiocarcinoma cell death through alteration of DNA methylation status. PLoS One, 10, 0120545.

Park M-T, Lee S-J (2003). Cell cycle and cancer. J Biochem Mol Biol, 36, 60-5.

Sanaei M, Kavoosi F (2019). Effects of 5-aza-2'-deoxycytidine and Valproic Acid on Epigenetic-modifying DNMT1 Gene Expression, Apoptosis Induction and Cell Viability in Hepatocellular Carcinoma WCH-17 cell line. Iran J Pediat Hematol Oncol, 9, 17-23

Sanaei M, Kavoosi F (2019). Effect of 5-aza-2'-deoxycytidine in comparison to valproic acid and trichostatin $\mathrm{A}$ on histone deacetylase 1, DNA methyltransferase 1, and CIP/KIP family (p21, p27, and p57) genes expression, cell growth inhibition, and apoptosis induction in colon cancer SW480 cell line. Adv Biomed Res, 8, 52.

Sanaei M, Kavoosi F (2018). Effect of curcumin and trichostatin A on the expression of DNA methyltransfrase 1 in
Epigenetic Reactivation of Tumor Suppressor Genes

hepatocellular carcinoma cell line hepa 1-6. Iran J Pediat Hematol Oncol, 8, 193-201.

Sanaei M, Kavoosi F, Roustazadeh A, et al (2018). Effect of genistein in comparison with trichostatin a on reactivation of DNMTs genes in hepatocellular carcinoma. $J$ Clin Translat Hepatol, 6, 141.

Sanaei M, Kavoosi F, Salehi H (2017). Genistein and trichostatin a induction of estrogen receptor alpha gene expression, apoptosis and cell growth inhibition in hepatocellular carcinoma HepG 2 cells. Asian Pac J Cancer Prev, 18, 3445.

Sarabi MM, Naghibalhossaini F (2015). Association of DNA methyltransferases expression with global and gene-specific DNA methylation in colorectal cancer cells. Cell Biochem Funct, 33, 427-33.

Shin J-Y, Kim H-S, Park J, et al (2000). Mechanism for inactivation of the KIP family cyclin-dependent kinase inhibitor genes in gastric cancer cells. Cancer Res, 60, 262-5.

Song J, Jin E-H, Kim D, et al (2015). MicroRNA-222 regulates MMP-13 via targeting HDAC-4 during osteoarthritis pathogenesis. BBA Clinical, 3, 79-89.

Thakur VS, Gupta K, Gupta S (2011). Green tea polyphenols causes cell cycle arrest and apoptosis in prostate cancer cells by suppressing class I histone deacetylases. Carcinogenesis, 33, 377-84.

Tsou JA, Hagen JA, Carpenter CL, Laird-Offringa IA (2002). DNA methylation analysis: a powerful new tool for lung cancer diagnosis. Oncogene, 21, 5450-61.

Yan B, Li X, Johnson A, et al (2015). Epigenetic drugs for cancer therapy. Epigenet Gene Exp Regulat, 18, 397-423.

Yang P-M, Lin Y-T, Shun C-T, et al (2013). Zebularine inhibits tumorigenesis and stemness of colorectal cancer via p53-dependent endoplasmic reticulum stress. Sci Rep, 3, 3219 .

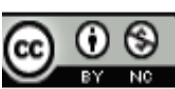

This work is licensed under a Creative Commons AttributionNon Commercial 4.0 International License. 